\title{
The role of anticoagulants, antiplatelet agents, and their reversal strategies in the management of intracerebral hemorrhage
}

\author{
Robert F. James, M.D., ${ }^{1}$ Viktoras Palys, M.D., ${ }^{2}$ Jason R. Lomboy, B.A., ${ }^{1}$ \\ J. Richard LAMm JR., B.S., ${ }^{1}$ aNd SCOTT D. Simon, M.D. ${ }^{2}$ \\ ${ }^{I}$ Division of Neurosurgery, Department of Surgery, East Carolina University Brody School of Medicine, \\ Greenville, North Carolina; and ${ }^{2}$ Department of Neurosurgery, Virginia Commonwealth University School of \\ Medicine, Richmond, Virginia
}

\begin{abstract}
New anticoagulant and antiplatelet medications have been approved and are prescribed with increased frequency. Intracranial hemorrhage is associated with the use of these medications. Therefore, neurosurgeons need to be aware of these new medications, how they are different from their predecessors, and the strategies for the urgent reversal of their effects. Utilization of intraluminal stents by endovascular neurosurgeons has resulted in the need to have a thorough understanding of antiplatelet agents. Increased use of dabigatran, rivaroxaban, and apixaban as oral anticoagulants for the treatment of atrial fibrillation and acute deep venous thrombosis has increased despite the lack of known antidotes to these medications.

(http://thejns.org/doi/abs/10.3171/2013.2.FOCUS1328)
\end{abstract}

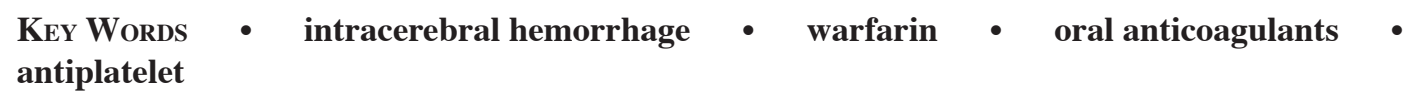

$\mathrm{N}$ ONTRAUMATIC spontaneous ICH may occur in patients taking antiplatelet and/or anticoagulant medications and is associated with worse outcomes and increased mortality. $8,10,11,21,23,25,36,57,60,70$ Difficulty or delay in the reversal of the effects of anticoagulant medications can result in hematoma expansion or delayed surgical evacuation. By comparison, reversal of antiplatelet medication in a similar setting still has unproven benefit. Recently, FDA-approved oral antiplatelet and anticoagulant medications have found increased usage, but introduce new challenges into the emergency management of antiplatelet- and anticoagulant-related $\mathrm{ICH}$. In this paper we review the relevant literature on antiplatelet- and anticoagulant-related ICH to familiarize practicing neurosurgeons with the medications now available, and to provide strategies for the emergency reversal of these medications, some of which have no direct antidote.

\footnotetext{
Abbreviations used in this paper: $\mathrm{AF}=$ atrial fibrillation; $\mathrm{DVT}=$ deep venous thrombosis; FFP = fresh-frozen plasma; ICH = intracerebral hemorrhage; INR = international normalized ratio; $\mathrm{PCC}=$ prothrombin complex concentrate; rVIIa = recombinant factor VIIa.
}

\section{Anticoagulant-Related ICH}

Anticoagulation medications are important treatments for numerous medical conditions including DVT, pulmonary embolism, and nonvalvular AF. Unfortunately, these medications are associated with an increased risk of ICH. Often the cause of the hemorrhage is directly related to a supratherapeutic effect of the anticoagulant. In other situations therapeutic levels can exacerbate an $\mathrm{ICH}$ of an alternate origin (such as trauma or cerebral aneurysm rupture).

All of the anticoagulant medications alter the coagulation cascade at various points along the extrinsic, intrinsic, or common pathways with an ultimate goal of reduced fibrin formation (Fig. 1). Because of the frequency that neurosurgeons are consulted to aid in the management of patients with anticoagulant-related $\mathrm{ICH}$, neurosurgeons should at least maintain a cursory understanding of these pathways and how they relate to the various anticoagulant medications.

Injectable anticoagulants (unfractionated heparin and enoxaparin) are most commonly used during admission to a medical facility, whereas the most commonly pre- 
R. F. James et al.

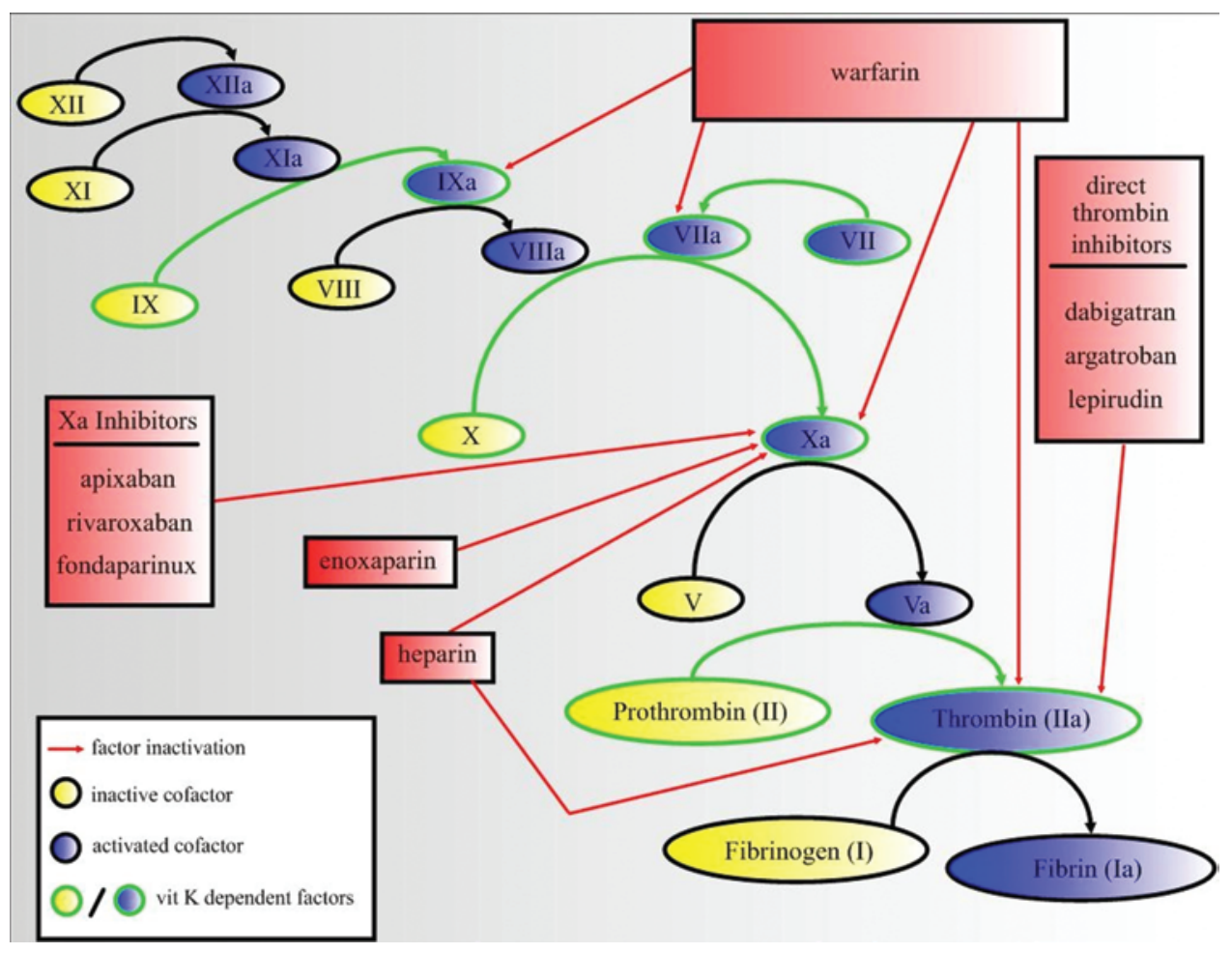

FIG. 1. The clotting cascade including common anticoagulant medications and their site of action. vit = vitamin.

scribed outpatient anticoagulant is warfarin. Warfarin's immediate predecessor was designed as a rodenticide; in the $1950 \mathrm{~s}$, warfarin began common usage as a medical anticoagulation therapy? Warfarin is a vitamin K antagonist and prevents the hepatic formation of the vitamin $\mathrm{K}$-dependent clotting factors (II, VII, IX, and X). Numerous randomized trials and meta-analyses have confirmed warfarin is highly effective at reducing the risk of stroke from $\mathrm{AF}^{75}$ However, genetic polymorphisms, several common medications, as well as changes in a patient's diet can drastically alter the anticoagulation effect, which is compounded by warfarin's relatively narrow therapeutic window. As a result, frequent drug monitoring with a prothrombin time and the INR is required. Even with frequent drug monitoring, high INR levels are frequently encountered in the outpatient setting and medication adjustments must be made. The most frequently recommended INR level for the treatment of AF is between 2 and 3. Even in the setting of strict INR monitoring during clinical trials, it can be difficult to maintain patients in this narrow therapeutic window, and subtherapeutic and supratherapeutic levels are common. ${ }^{7}$ International normalized ratio levels greater than 4.0 have been reported to be associated with significantly increased risk for ICH. ${ }^{21}$ Warfarin-related ICH patients have a significantly increased risk of hematoma expansion (OR 6.2, 95\% CI 1.7-22.9) compared with ICH patients not receiving anticoagulant therapy ${ }^{23}$ After decades in which warfarin was the only oral anticoagulation therapy available to patients, new oral medications have recently gained approval by the FDA (www.fda.gov) that have much similar stroke protection, more reliable dose-response relationships, and do not require blood-level monitoring. ${ }^{12,54,75}$ These medi- cations include dabigatran (a direct thrombin inhibitor), and rivaroxaban and apixaban, direct inhibitors of factor $\mathrm{Xa} .{ }^{12}$ Many cardiologists and neurologists have been increasingly prescribing these medications over the last few years. However, this enthusiasm has been tempered by the lack of an antidote and fear of being unable to safely manage patients taking these new medications who experience anticoagulant-related ICH. The silver lining to these uncertainties is that the incidence of major hemorrhage in Phase III clinical trials for these new oral anticoagulants is lower than that of warfarin. ${ }^{15,29,52}$

A prospective randomized, open-label trial (Randomized Evaluation of Long-Term Anticoagulation Therapy, or RE-LY) compared 2 blinded doses of dabigatran (110 $\mathrm{mg}$ twice daily and $150 \mathrm{mg}$ twice daily) with open-label adjusted dose warfarin (INR target 2.0-3.0) in 18,113 patients. Dabigatran $150 \mathrm{mg}$ twice daily was found to be significantly better than warfarin at preventing stroke or systemic embolism, and dabigatran $110 \mathrm{mg}$ twice daily was demonstrated as noninferior to warfarin. Both doses of dabigatran were found to produce a significant reduction in the rates of ICH and hemorrhagic stroke compared with warfarin (dabigatran $0.12 \%, 0.10 \%$ vs warfarin $0.38 \%$ per year; RR 0.31 and $0.26 ; \mathrm{p}<0.01$ [both]). ${ }^{15}$ Only the $150-\mathrm{mg}$ dose tested in the study is available in the US. Similar results were found in other prospective randomized, double-blind Phase III clinical trials including the Rivaroxaban Once Daily Oral Direct Factor Xa Inhibition Compared with Vitamin K Antagonism for Prevention of Stroke and Embolism Trial in Atrial Fibrillation (ROCKET-AF) and Apixaban for Reduction in Stroke and Other Thromboembolic Events in Atrial Fibrillation (ARISTOTLE) trial, in which rivaroxaban 
and apixaban were both found to demonstrate statistically significant reductions in hemorrhagic stroke compared with warfarin. ${ }^{29,52}$ Recently, the American College of Chest Physicians published their newest recommendations for antithrombotic therapy for atrial fibrillation; they are now suggesting dabigatran $150 \mathrm{mg}$ twice daily rather than warfarin when oral anticoagulant therapy is recommended. ${ }^{77}$ As these newer oral anticoagulants are increasingly prescribed more frequently, we hope a realworld decrease in the frequency of anticoagulant-related ICH will follow. Nevertheless, there will be patients with anticoagulant-related $\mathrm{ICH}$ who need emergency attention and immediate reversal of the anticoagulating effects.

Hematoma expansion is common in the setting of anticoagulant-related $\mathrm{ICH}$, leading to more deaths. Correcting the INR to 1.3 or less within 2 hours has been shown to decrease hematoma expansion. ${ }^{33}$ Advances and improvements have been made in methods for reversal of warfarin (a summary of common anticoagulants and their reversal methods can be found in Table 1). The first consideration for emergency management of anticoagulant-related $\mathrm{ICH}$ is to stop the anticoagulant agent. Blood pressure should be controlled, although there is little evidence to support a specific blood pressure goal. The authors' preference is to maintain the systolic blood pressure below $160 \mathrm{~mm} \mathrm{Hg}$. Medical management of elevated intracranial pressure should be initiated immediately. Fast-acting agents for reversal of anticoagulation by factor replacement include FFP, PCC, and rVIIa. Of these, FFP (the historical standard of care) is relatively deficient in factor IX, requires large volume infusion, and can lead to complications such as pulmonary edema and delayed reversal of INR. ${ }^{41}$ Recombinant factor VIIa is effective for immediate INR reversal and prevention of hematoma expansion, but is associated with increased thrombotic complications such as myocardial infarction, pulmonary embolism, and DVT. Recombinant factor VIIa has not been shown to improve survival or functional outcome and is generally not recommended for reversal in anticoagulant-related ICH. ${ }^{39,78}$ Prothrombin complex concentrate is increasing in popularity as a low-volume, rapidreversal agent, and has been reported as superior to FFP in several studies. ${ }^{49,68,72,76}$ Individualized dosing of PCC may be the most effective method of reversal. In 1 study, individualized dosing of PCC based on the patient's body weight and initial INR was superior at reaching the target INR 15 minutes after dosing compared with the standard dosage of PCC. ${ }^{72}$ Similar data has led to support for PCC as the standard of care at many institutions.

Prothrombin complex concentrate formulations vary worldwide, with the US receiving FDA approval for "3-factor" PCC (II, IX, X) whereas many clinical studies conducted outside the US involve "4-factor" PCC, which includes factor VII. It is unclear whether the difference in these preparations is significant and any review of the literature on this topic needs to have this critique in mind. ${ }^{55}$ Even though PCC formulations have variable amounts of factor VII, PCC replaces multiple factors compared with rVIIa, and is cost effective when compared with FFP for serious bleeding. ${ }^{32}$ When reversing warfarin one must remember that treatment with a fast-acting agent alone is not enough for a sustained reversal effect. It is necessary to also administer vitamin $\mathrm{K}$ (orally or intravenously) to maintain INR reversal. ${ }^{16}$ In emergency situations, vitamin $\mathrm{K}$ should not be used alone, but should be used in conjunction with faster-acting agents because vitamin $\mathrm{K}$ can take up to 24 hours to achieve INR correction. ${ }^{16}$ Additionally, intravenous (versus oral) vitamin $\mathrm{K}$ is associated with a low risk of anaphylaxis, but generally remains the preferred route of administration.

New oral anticoagulants (dabigatran, rivaroxaban, apixaban) have recently been approved by the FDA for use in patients with AF for the prevention of stroke and for the treatment of acute DVT (rivaroxaban). The advantages of these medications include a more reliable anticoagulant effect, decreased risk of associated $\mathrm{ICH}$, and no need for monitoring of therapeutic levels. The biggest disadvantage of these medications is the lack of an antidote. ${ }^{41}$ For recent dosing or recent overdose, consider oral activated charcoal to help absorb the drug and reduce the bioavailability. Strategies for reversal may include FFP, PCC, and/or rVIIa administration, but current studies show that for dabigatran these methods may be ineffective and only moderately effective with rivaroxaban. ${ }^{20}$ Current evidence is too weak to support a specific reversal protocol for any of these medications; thus, supportive care is essential for $\mathrm{ICH}$ related to these medications. As dabigatran is cleared by renal excretion, optimizing renal function is necessary. Hemodialysis has been suggested as an emergency means of removal of dabigatran, and may be the most effective means in patients with impaired creatinine clearance. With dabigatran, a normal activated partial thromboplastin time suggests no active anticoagulation effect and can be used to guide reversal therapy or timing of surgical intervention..$^{73}$ For rivaroxaban and apixaban, emergency reversal with PCC is likely the most effective option as both are $\mathrm{Xa}$ inhibitors and PCC is more likely to be effective with these medications than with dabigatran (a direct thrombin inhibitor; Fig. 1). Confirmation of normal antifactor Xa assay activity is useful in showing that rivaroxaban and apixaban are no longer causing an anticoagulation effect. ${ }^{54}$

In the case of anticoagulant-related $\mathrm{ICH}$, warfarin remains the most commonly prescribed oral anticoagulant, but due to improved dose response, larger therapeutic windows, and reduced risk of $\mathrm{ICH}$, newer oral agents such as dabigatran, rivaroxaban, and apixaban are being used with increasing frequency. Having a basic appreciation for the pharmacokinetics of these medications, including possible reversal strategies in the setting of $\mathrm{ICH}$, are essential for patient safety. Although there are no specific antidotes to the newer oral anticoagulants, reversal strategies do exist and may be implemented in emergency situations. Additional research studies evaluating the best methods for reversal of these medications are ongoing and much needed.

\section{Antiplatelet-Related ICH}

Antiplatelet medication has been shown to be a risk factor for spontaneous ICH as well as increased ICH volume and increased mortality, but the exact increase has 
R. F. James et al.

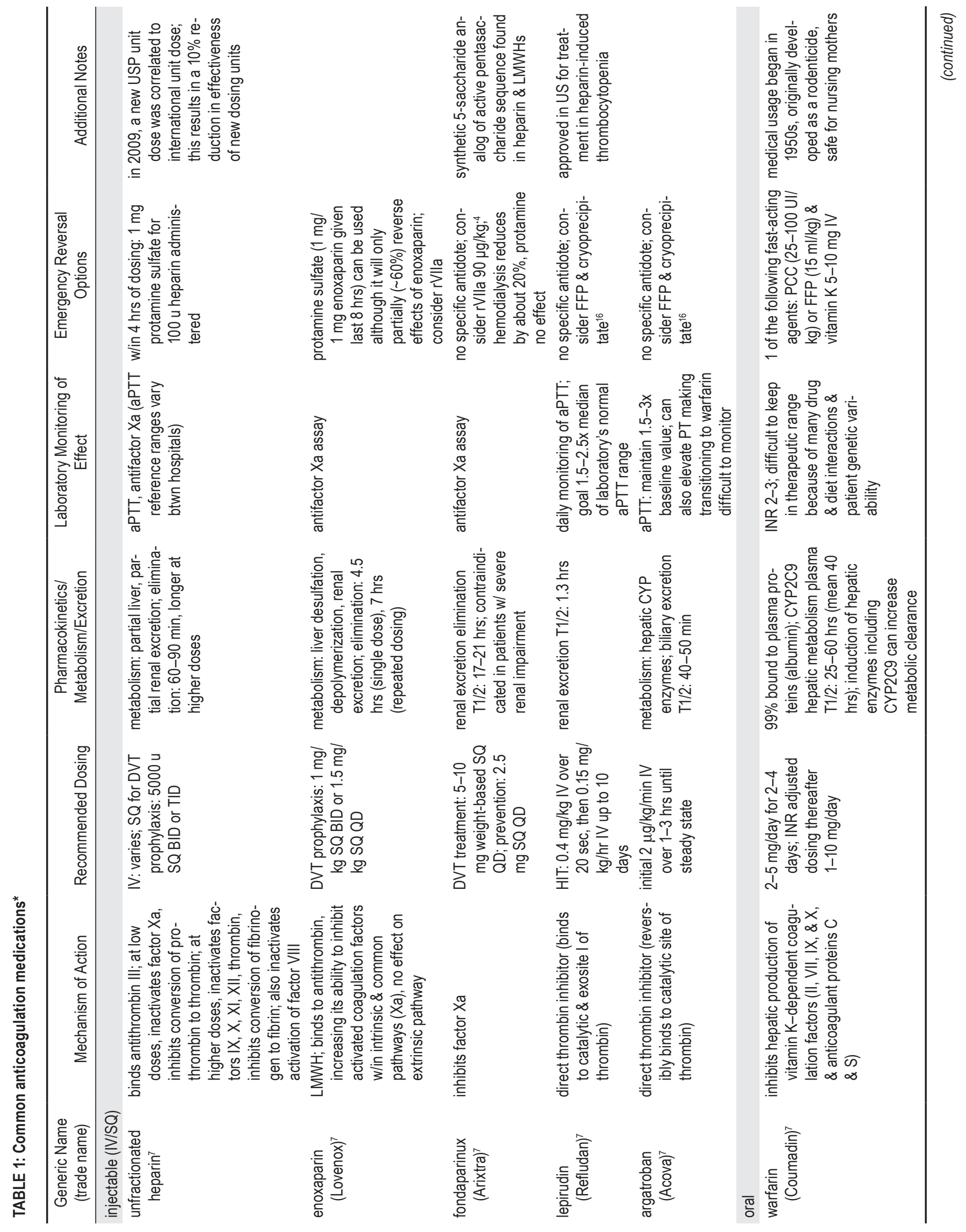


Anticoagulant- and antiplatelet-related intracerebral hemorrhage

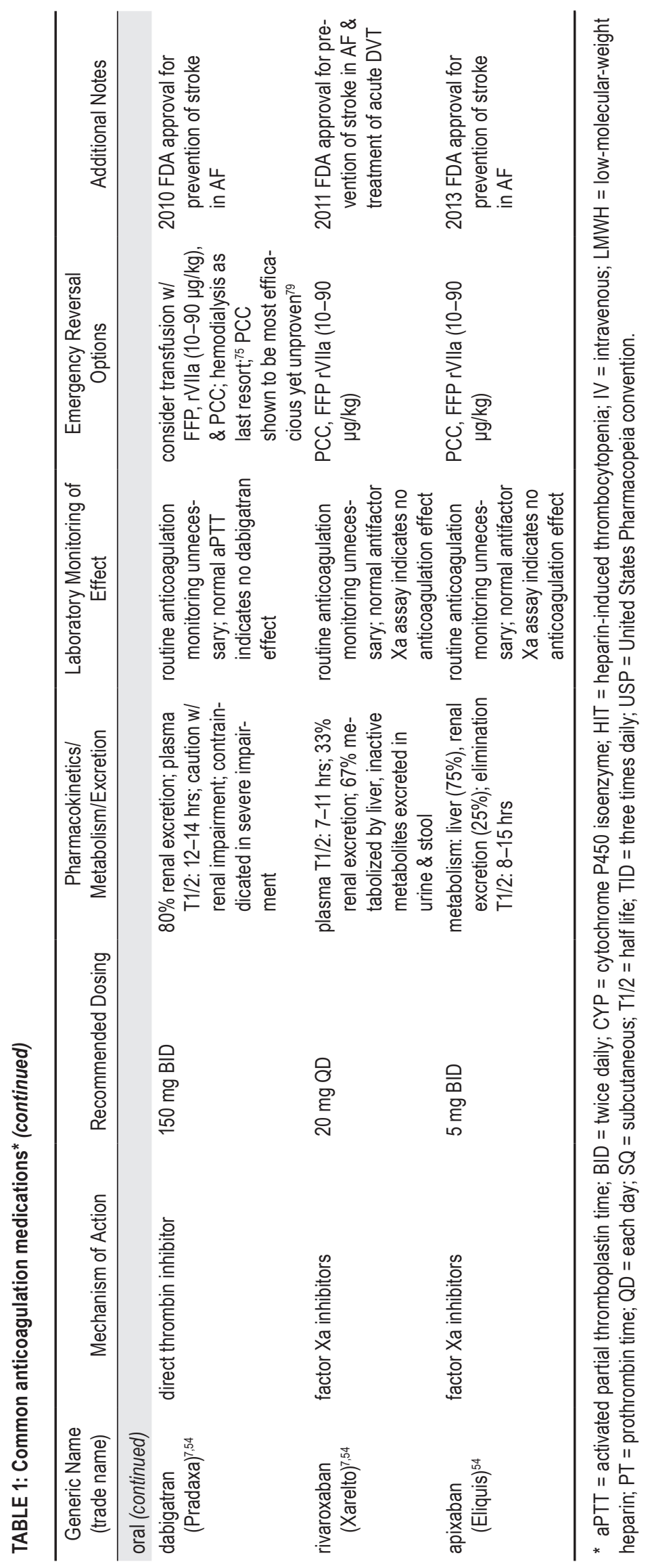


not been consistently demonstrated for any specific drug among many reports..$^{8,10,11,25,37,57,60,70}$ The risk for ICH appears to be dose dependent with aspirin, the most studied agent, but exists with other agents as well. 1,6,11,36,56,59,66,67, 69,71 Naidech et al. ${ }^{42-44}$ demonstrated that increased platelet inhibition (as measured with VerifyNow ASA and P2Y12 tests [Accumetrics, Inc.] for aspirin and clopidogrel, respectively), correlated with increased ICH volume growth at 12 hours, volume of intraventricular hemorrhage, increased chance of death at 14 days, and poor outcome at 3 months. Additionally, Naidech et al. ${ }^{46}$ demonstrated that the chance of undergoing a craniotomy for $\mathrm{ICH}$, when controlling for size of hemorrhage and location, was increased with pre-event aspirin use and platelet inhibition as determined by VerifyNow ASA. In a retrospective comparison of patients presenting with $\mathrm{ICH}$ on aspirin or Plavix (clopidogrel), Campbell et al. ${ }^{9}$ noted larger ICH size and decreased chance of discharge to home in the clopidogrel group. They also noted increased mortality, but this failed to reach statistical significance.

Given the likely association between antiplatelet use, $\mathrm{ICH}$ volume, intraventricular hemorrhage, and death, 1 possible strategy for reducing hematoma growth and mortality is to reverse the effect of antiplatelet medications by administering a platelet transfusion. ${ }^{3,40}$ A platelet transfusion of 10-12.5 units of platelets has been shown to restore normal platelet function in patients on aspirin and clopidogrel. ${ }^{74}$ Desmopressin has been known to increase platelet reactivity in patients treated with aspirin by releasing a greater number of von Willibrand multimers. ${ }^{24}$ The role of intravenous desmopressin in decreasing bleeding during cardiac surgery is controversial, whereas rVIIa has shown promise preclinically as a possible agent. $2,30,53$

Some authors have described variations of platelet reversal regimens as standard at their centers. ${ }^{3,45}$ Naidech et al. ${ }^{45}$ evaluated this hypothesis by treating 45 patients with spontaneous $\mathrm{ICH}$ and an assay consistent with platelet inhibition, with a platelet transfusion within 12 hours of admission. Transfusion resulted in a decrease of platelet inhibition out of therapeutic range for most patients, although the dose of platelets was not standardized. Within their cohort, they identified 32 patients with a high degree of platelet inhibition, and within this subset, those who received a transfusion within 12 hours had less hematoma growth and a better outcome than those who received a transfusion after 12 hours.

The limited positive outcome of antiplatelet reversal is counterbalanced by many studies showing no benefit. Ducruet et al. ${ }^{19}$ compared the clinical course and outcomes in 35 patients presenting with $\mathrm{ICH}$ on antiplatelet therapy reversed with platelet transfusion, to 31 patients without platelet transfusion, and found no difference in hematoma growth or outcome. Nishijima et al. ${ }^{47}$ performed a retrospective meta-analysis of $\mathrm{ICH}$ secondary to trauma in patients receiving antiplatelet medication before injury. These authors identified 635 studied patients in 5 retrospective reviews in which 3 studies revealed no benefit, 1 revealed higher mortality in the transfusion cohort, and 1 demonstrated decreased mortality with transfusion (although there were 92 patients in the transfusion arm and
19 in the no-transfusion arm). ${ }^{47}$ Another literature review by Campbell et al. ${ }^{8}$ also found no clear evidence of benefit with platelet transfusion, but suggested the following protocol as a starting point for further investigation: 1) for a patient with ICH on aspirin alone, transfuse 1 pack of platelets; 2) for a patient with a small ICH on clopidogrel or a combination of therapies, administer 2 units of platelets; 3) for patients with large ICH on clopidogrel or multiple agents, administer desmopressin $3 \mathrm{mcg} / \mathrm{kg}$ intravenously and 1 pack of platelets every 12 hours for 48 hours. There is a randomized trial currently underway to evaluate antiplatelet agent reversal in ICH (Platelet Transfusion in Cerebral Hemorrhage [PATCH] trial). ${ }^{17}$

One limitation of testing strategies that use platelet assays is the variability in the types of assays available. As described in Table 2, platelet activity and levels of inhibition can be measured by many different types of platelet function assays. There are multiple laboratory and point-of-care testing systems available and results are reported in units of time, change in light transmission, platelet count, surface area covered, and flow cytometry. ${ }^{62}$ On many of these systems, high platelet inhibition has been associated with bleeding events and low platelet inhibition with in-stent thrombosis after coronary artery stenting. ${ }^{5,64}$ Moreover, aspirin and clopidogrel resistance has been associated with poor outcome in patients with stroke. ${ }^{31,61}$ Nonetheless, multiple comparison studies have been unable to establish a correlation between the results of the various testing systems. ${ }^{28,35,38,48,50,51}$ Furthermore, point-of-care testing tends to have greater inaccuracy than hematology lab testing. ${ }^{62}$ There is currently no established standard to define inappropriate platelet activity. ${ }^{62}$

The impact of these limitations is illustrated in multiple studies that have attempted to use platelet assayguided therapy protocols to tailor patient medical regimens with poor results. Collet et al. ${ }^{13}$ randomized patients undergoing coronary artery stenting into 2 groups, 1 receiving antiplatelet medication without monitoring and 1 with monitoring utilizing the VerifyNow P2Y12 assay with medication adjustments made as necessary. At 1 year there was no difference between the 2 groups in any of the outcome measures, including death, myocardial infarction, stroke, urgent revascularization, or major bleeding event. ${ }^{13}$ Along similar lines, Depta et al. ${ }^{18}$ retrospectively reviewed patients with ischemic stroke who were subsequently placed on antiplatelet therapy, comparing patients given antiplatelet medication without testing to those followed by platelet aggregometry with appropriate dose adjustments. The authors describe a higher rate of death, ischemic events, and bleeding in the patients followed by aggregometry who subsequently received dose increases. ${ }^{18}$

Stopping antiplatelet medication is not without risk. Withdrawal of antiplatelet agents before elective surgery has been shown to be a risk factor for heart attack and death. ${ }^{14}$ Cessation of antiplatelet therapy for those with cardiac stents is associated with a high rate of stent thrombosis and infarction, especially for drug-eluting stents. $^{22,34,63}$ Patients with intracranial stents are at increased risk of stroke and transient ischemic attack with early withdrawal of an antiplatelet agent or resistance. ${ }^{58}$ 
Anticoagulant- and antiplatelet-related intracerebral hemorrhage

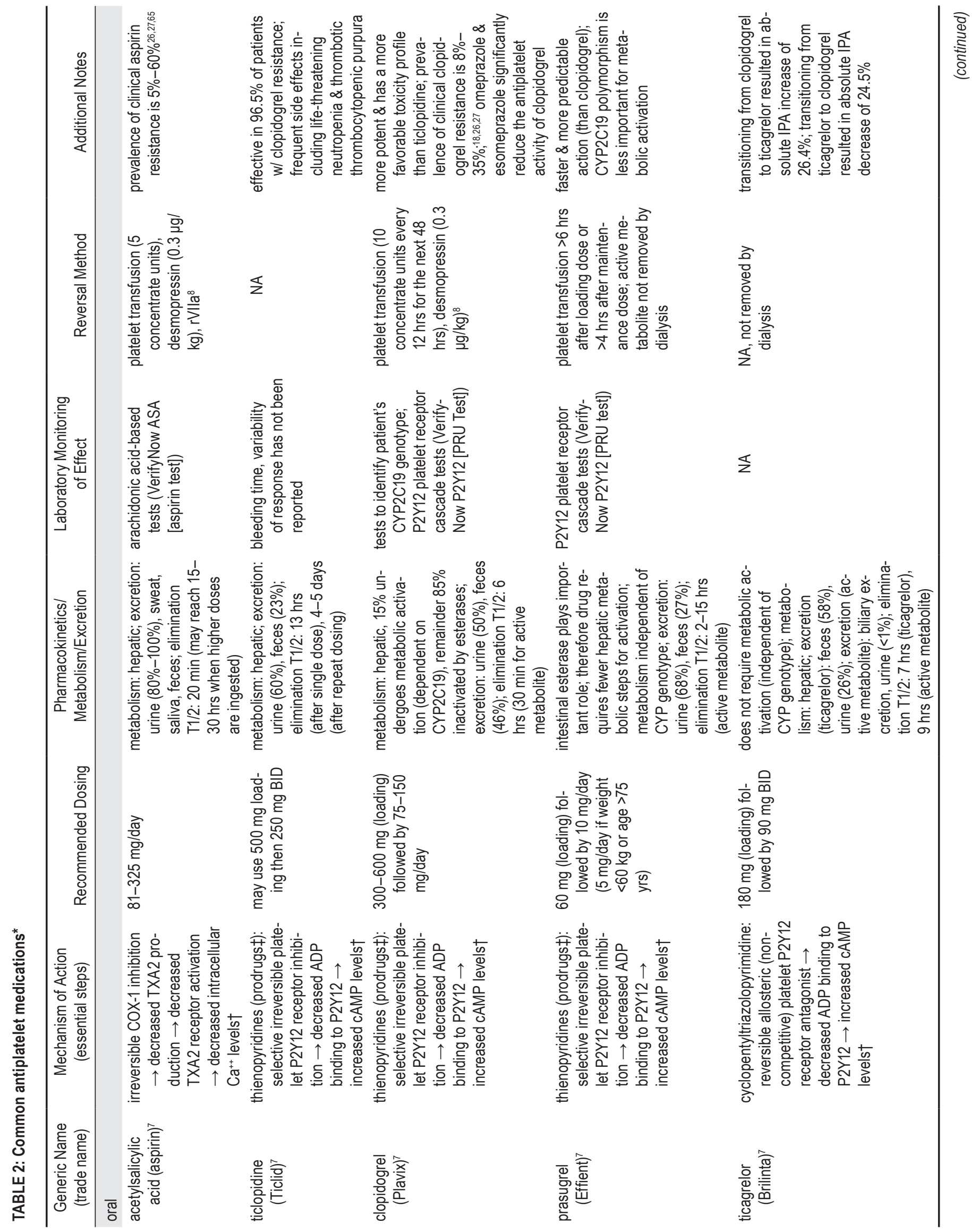


R. F. James et al.

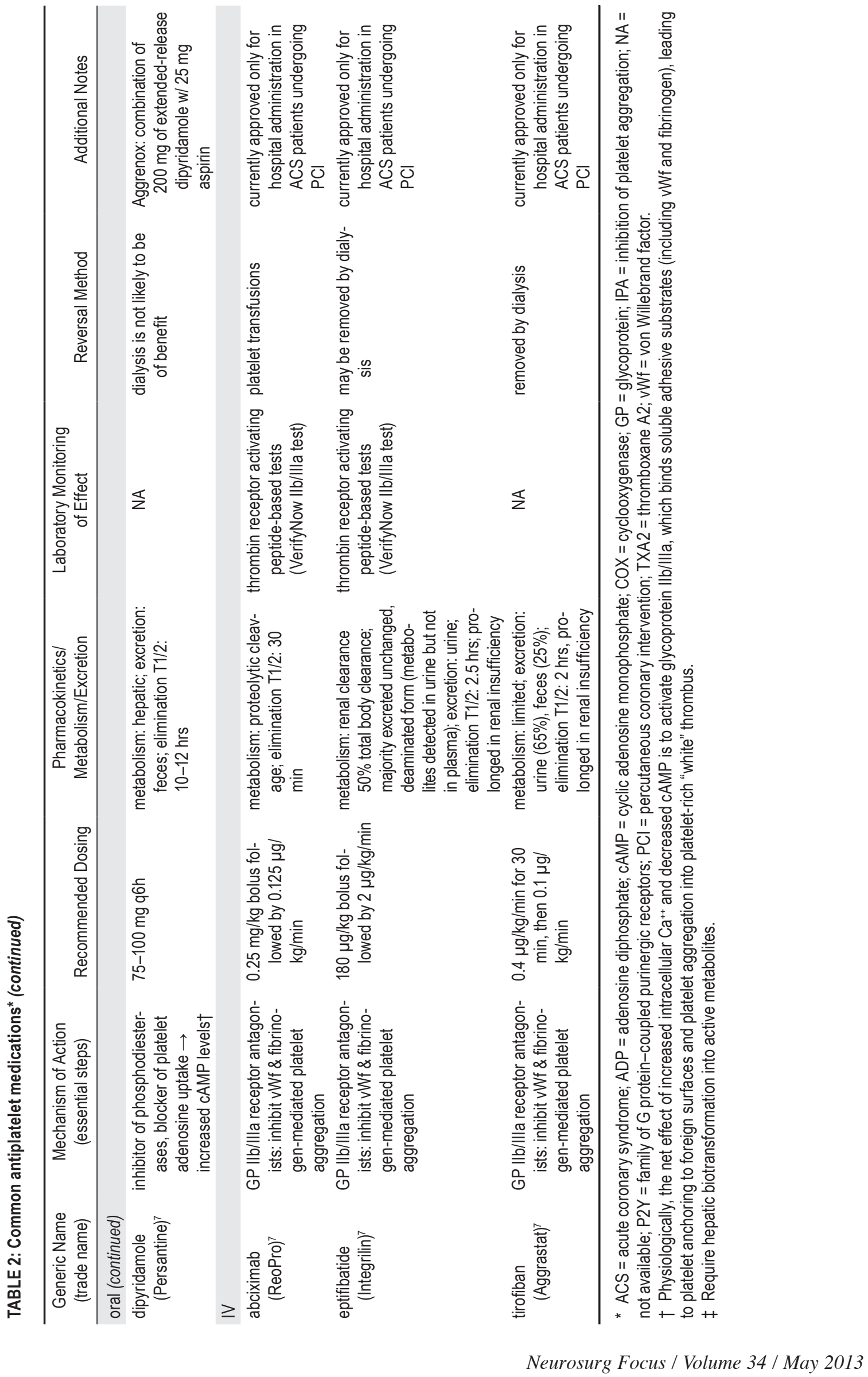




\section{Anticoagulant- and antiplatelet-related intracerebral hemorrhage}

When considering antiplatelet-related $\mathrm{ICH}$, determining the exact role that antiplatelet agents play in $\mathrm{ICH}$ formation, growth, and outcome as well as the role for antiplatelet reversal in patients with ICH requires significantly more clinical data. Currently, there is no well-supported algorithm for treating these patients. The decision to stop all antiplatelet medication needs to be carefully considered, weighing the size and morbidity of the ICH against the reason the agents were initiated. The value of platelet function assays in patients presenting with $\mathrm{ICH}$ is uncertain at this time. Reversing antiplatelet medication with transfusion, desmopressin, or other factors is not currently supported by strong clinical data and should be considered investigational at this juncture.

\section{Conclusions}

Anticoagulant- and antiplatelet-related ICH involve the risks of hematoma expansion and poor outcome. Reversal of antiplatelet medications is an option to prevent worsening of the $\mathrm{ICH}$, but the effectiveness for improved clinical outcomes remains unproven. Reversal of warfarin to prevent enlargement of the $\mathrm{ICH}$ is recommended. Physicians should consider utilizing PCC over FFP in addition to vitamin $\mathrm{K}$ for the reversal of warfarin anticoagulation. Dabigatran reversal may benefit from PCC but the evidence is weak and efforts should be directed toward improving renal clearance with consideration of hemodialysis in emergency situations. Rivaroxaban and apixaban are more likely to benefit from PCC administration than dabigatran but are unlikely to benefit from hemodialysis.

\section{Disclosure}

Dr. James is an investor/stockholder in Remedy Pharmaceuticals, Inc.

Author contributions to the study and manuscript preparation include the following. Conception and design: James. Acquisition of data: all authors. Analysis and interpretation of data: all authors. Drafting the article: James, Simon. Critically revising the article: James, Simon. Reviewed submitted version of manuscript: all authors. Approved the final version of the manuscript on behalf of all authors: James. Administrative/technical/material support: James. Study supervision: James. Table creation: Palys, Lomboy. Figure preparation: Lamm.

\section{Acknowledgment}

The authors would like to thank Kristin J. Wainwright for her help in editing the manuscript.

\section{References}

1. Akbari SH, Reynolds MR, Kadkhodayan Y, Cross DT III, Moran CJ: Hemorrhagic complications after prasugrel (Effient) therapy for vascular neurointerventional procedures. J Neurointerv Surg [epub ahead of print], 2012

2. Altman R, Scazziota A, DE Lourdes Herrera M, Gonzalez C: Recombinant factor VIIa reverses the inhibitory effect of aspirin or aspirin plus clopidogrel on in vitro thrombin generation. J Thromb Haemost 4:2022-2027, 2006

3. Beshay JE, Morgan H, Madden C, Yu W, Sarode R: Emergency reversal of anticoagulation and antiplatelet therapies in neurosurgical patients. A review. J Neurosurg 112:307-318, 2010

4. Bijsterveld NR, Moons AH, Boekholdt SM, van Aken BE,
Fennema H, Peters RJ, et al: Ability of recombinant factor VIIa to reverse the anticoagulant effect of the pentasaccharide fondaparinux in healthy volunteers. Circulation 106:25502554, 2002

5. Breet NJ, van Werkum JW, Bouman HJ, Kelder JC, Ruven HJ, Bal ET, et al: Comparison of platelet function tests in predicting clinical outcome in patients undergoing coronary stent implantation. JAMA 303:754-762, 2010

6. Broderick JP, Diringer MN, Hill MD, Brun NC, Mayer SA, Steiner T, et al: Determinants of intracerebral hemorrhage growth: an exploratory analysis. Stroke 38:1072-1075, 2007

7. Brunton LL, Chabner BA, Knollmann BC: Goodman \& Gilman's The Pharmacological Basis of Therapeutics, ed 12. New York: McGraw-Hill, 2011

8. Campbell PG, Sen A, Yadla S, Jabbour P, Jallo J: Emergency reversal of antiplatelet agents in patients presenting with an intracranial hemorrhage: a clinical review. World Neurosurg 74:279-285, 2010

9. Campbell PG, Yadla S, Sen AN, Jallo J, Jabbour P: Emergency reversal of clopidogrel in the setting of spontaneous intracerebral hemorrhage. World Neurosurg 76:100-104, 2011

10. Cantalapiedra A, Gutierrez O, Tortosa JI, Yañez M, Dueñas M, Fernandez Fontecha E, et al: Oral anticoagulant treatment: risk factors involved in 500 intracranial hemorrhages. J Thromb Thrombolysis 22:113-120, 2006

11. Caso V, Paciaroni M, Venti M, Alberti A, Palmerini F, Milia P, et al: Effect of on-admission antiplatelet treatment on patients with cerebral hemorrhage. Cerebrovasc Dis 24:215-218, 2007

12. Cervera A, Amaro S, Chamorro A: Oral anticoagulant-associated intracerebral hemorrhage. J Neurol 259:212-224, 2012

13. Collet JP, Cuisset T, Rangé G, Cayla G, Elhadad S, Pouillot $\mathrm{C}$, et al: Bedside monitoring to adjust antiplatelet therapy for coronary stenting. N Engl J Med 367:2100-2109, 2012

14. Collet JP, Montalescot G, Blanchet B, Tanguy ML, Golmard JL, Choussat R, et al: Impact of prior use or recent withdrawal of oral antiplatelet agents on acute coronary syndromes. Circulation 110:2361-2367, 2004

15. Connolly SJ, Ezekowitz MD, Yusuf S, Eikelboom J, Oldgren $\mathrm{J}$, Parekh A, et al: Dabigatran versus warfarin in patients with atrial fibrillation. N Engl J Med 361:1139-1151, 2009

16. Crowther MA, Ageno W, Schnurr T, Manfredi E, Kinnon K, Garcia D, et al: Oral vitamin K produces a normal INR within 24 hours of its administration in most patients discontinuing warfarin. Haematologica 90:137-139, 2005

17. de Gans K, de Haan RJ, Majoie CB, Koopman MM, Brand A, Dijkgraaf MG, et al: PATCH: platelet transfusion in cerebral haemorrhage: study protocol for a multicentre, randomised, controlled trial. BMC Neurol 10:19, 2010

18. Depta JP, Fowler J, Novak E, Katzan I, Bakdash S, KottkeMarchant K, et al: Clinical outcomes using a platelet function-guided approach for secondary prevention in patients with ischemic stroke or transient ischemic attack. Stroke 43:2376-2381, 2012

19. Ducruet AF, Hickman ZL, Zacharia BE, Grobelny BT, DeRosa PA, Landes E, et al: Impact of platelet transfusion on hematoma expansion in patients receiving antiplatelet agents before intracerebral hemorrhage. Neurol Res 32:706-710, 2010

20. Eerenberg ES, Kamphuisen PW, Sijpkens MK, Meijers JC, Buller HR, Levi M: Reversal of rivaroxaban and dabigatran by prothrombin complex concentrate: a randomized, placebocontrolled, crossover study in healthy subjects. Circulation 124:1573-1579, 2011

21. Fang MC, Chang Y, Hylek EM, Rosand J, Greenberg SM, Go AS, et al: Advanced age, anticoagulation intensity, and risk for intracranial hemorrhage among patients taking warfarin for atrial fibrillation. Ann Intern Med 141:745-752, 2004

22. Ferrari E, Benhamou M, Cerboni P, Marcel B: Coronary syndromes following aspirin withdrawal: a special risk for late stent thrombosis. J Am Coll Cardiol 45:456-459, 2005 
23. Flibotte JJ, Hagan N, O'Donnell J, Greenberg SM, Rosand J: Warfarin, hematoma expansion, and outcome of intracerebral hemorrhage. Neurology 63:1059-1064, 2004

24. Flordal PA, Sahlin S: Use of desmopressin to prevent bleeding complications in patients treated with aspirin. Br J Surg 80:723-724, 1993

25. Foerch C, Sitzer M, Steinmetz H, Neumann-Haefelin T: Pretreatment with antiplatelet agents is not independently associated with unfavorable outcome in intracerebral hemorrhage. Stroke 37:2165-2167, 2006

26. Fong J, Cheng-Ching E, Hussain MS, Katzan I, Gupta R: Predictors of biochemical aspirin and clopidogrel resistance in patients with ischemic stroke. J Stroke Cerebrovasc Dis 20:227-230, 2011

27. Fukuoka T, Furuya D, Takeda H, Dembo T, Nagoya H, Kato Y, et al: Evaluation of clopidogrel resistance in ischemic stroke patients. Intern Med 50:31-35, 2011

28. Godino C, Mendolicchio L, Figini F, Latib A, Sharp AS, Cosgrave J, et al: Comparison of VerifyNow-P2Y12 test and Flow Cytometry for monitoring individual platelet response to clopidogrel. What is the cut-off value for identifying patients who are low responders to clopidogrel therapy? Thromb J 7:4, 2009

29. Granger CB, Alexander JH, McMurray JJ, Lopes RD, Hylek EM, Hanna M, et al: Apixaban versus warfarin in patients with atrial fibrillation. N Engl J Med 365:981-992, 2011

30. Gratz I, Koehler J, Olsen D, Afshar M, DeCastro N, Spagna PM, et al: The effect of desmopressin acetate on postoperative hemorrhage in patients receiving aspirin therapy before coronary artery bypass operations. J Thorac Cardiovasc Surg 104:1417-1422, 1992

31. Grotemeyer KH, Scharafinski HW, Husstedt IW: Two-year follow-up of aspirin responder and aspirin non responder. A pilot-study including 180 post-stroke patients. Thromb Res 71: 397-403, 1993

32. Guest JF, Watson HG, Limaye S: Modeling the cost-effectiveness of prothrombin complex concentrate compared with fresh frozen plasma in emergency warfarin reversal in the United Kingdom. Clin Ther 32:2478-2493, 2010

33. Huttner HB, Schellinger PD, Hartmann M, Köhrmann M, Juettler E, Wikner J, et al: Hematoma growth and outcome in treated neurocritical care patients with intracerebral hemorrhage related to oral anticoagulant therapy: comparison of acute treatment strategies using vitamin $\mathrm{K}$, fresh frozen plasma, and prothrombin complex concentrates. Stroke 37:14651470,2006

34. Iakovou I, Schmidt T, Bonizzoni E, Ge L, Sangiorgi GM, Stankovic G, et al: Incidence, predictors, and outcome of thrombosis after successful implantation of drug-eluting stents. JAMA 293:2126-2130, 2005

35. Jakubowski JA, Li YG, Small DS, Payne CD, Tomlin ME, Luo J, et al: A comparison of the VerifyNow P2Y12 point-ofcare device and light transmission aggregometry to monitor platelet function with prasugrel and clopidogrel: an integrated analysis. J Cardiovasc Pharmacol 56:29-37, 2010

36. Lacut K, Le Gal G, Seizeur R, Prat G, Mottier D, Oger E: Antiplatelet drug use preceding the onset of intracerebral hemorrhage is associated with increased mortality. Fundam Clin Pharmacol 21:327-333, 2007

37. Lacut K, van der Maaten J, Le Gal G, Cornily G, Mottier D, Oger E: Antiplatelet drugs and risk of venous thromboembolism: results from the EDITH case-control study. Haematologica 93:1117-1118, 2008

38. Mangiacapra F, Patti G, Peace A, Gatto L, Vizzi V, Ricottini E, et al: Comparison of platelet reactivity and periprocedural outcomes in patients with versus without diabetes mellitus and treated with clopidogrel and percutaneous coronary intervention. Am J Cardiol 106:619-623, 2010

39. Mayer SA, Brun NC, Begtrup K, Broderick J, Davis S, Dir- inger MN, et al: Efficacy and safety of recombinant activated factor VII for acute intracerebral hemorrhage. N Engl J Med 358:2127-2137, 2008

40. McMillian WD, Rogers FB: Management of prehospital antiplatelet and anticoagulant therapy in traumatic head injury: a review. J Trauma 66:942-950, 2009

41. Mittal MK, Rabinstein AA: Anticoagulation-related intracranial hemorrhages. Curr Atheroscler Rep 14:351-359, 2012

42. Naidech AM, Bendok BR, Garg RK, Bernstein RA, Alberts MJ, Bleck TP, et al: Reduced platelet activity is associated with more intraventricular hemorrhage. Neurosurgery 65: 684-688, 2009

43. Naidech AM, Bernstein RA, Levasseur K, Bassin SL, Bendok $\mathrm{BR}$, Batjer HH, et al: Platelet activity and outcome after intracerebral hemorrhage. Ann Neurol 65:352-356, 2009

44. Naidech AM, Jovanovic B, Liebling S, Garg RK, Bassin SL, Bendok BR, et al: Reduced platelet activity is associated with early clot growth and worse 3-month outcome after intracerebral hemorrhage. Stroke 40:2398-2401, 2009

45. Naidech AM, Liebling SM, Rosenberg NF, Lindholm PF, Bernstein RA, Batjer HH, et al: Early platelet transfusion improves platelet activity and may improve outcomes after intracerebral hemorrhage. Neurocrit Care 16:82-87, 2012

46. Naidech AM, Rosenberg NF, Bernstein RA, Batjer HH: Aspirin use or reduced platelet activity predicts craniotomy after intracerebral hemorrhage. Neurocrit Care 15:442-446, 2011

47. Nishijima DK, Zehtabchi S, Berrong J, Legome E: Utility of platelet transfusion in adult patients with traumatic intracranial hemorrhage and preinjury antiplatelet use: a systematic review. J Trauma Acute Care Surg 72:1658-1663, 2012

48. Ozben S, Ozben B, Tanrikulu AM, Ozer F, Ozben T: Aspirin resistance in patients with acute ischemic stroke. J Neurol 258:1979-1986, 2011

49. Pabinger I, Brenner B, Kalina U, Knaub S, Nagy A, Ostermann H: Prothrombin complex concentrate (Beriplex P/N) for emergency anticoagulation reversal: a prospective multinational clinical trial. J Thromb Haemost 6:622-631, 2008

50. Paniccia R, Antonucci E, Gori AM, Marcucci R, Giglioli C, Antoniucci D, et al: Different methodologies for evaluating the effect of clopidogrel on platelet function in high-risk coronary artery disease patients. J Thromb Haemost 5:18391847,2007

51. Paniccia R, Antonucci E, Maggini N, Miranda M, Gori AM, Marcucci R, et al: Comparison of methods for monitoring residual platelet reactivity after clopidogrel by point-of-care tests on whole blood in high-risk patients. Thromb Haemost 104:287-292, 2010

52. Patel MR, Mahaffey KW, Garg J, Pan G, Singer DE, Hacke W, et al: Rivaroxaban versus warfarin in nonvalvular atrial fibrillation. N Engl J Med 365:883-891, 2011

53. Pleym H, Stenseth R, Wahba A, Bjella L, Tromsdal A, Karevold A, et al: Prophylactic treatment with desmopressin does not reduce postoperative bleeding after coronary surgery in patients treated with aspirin before surgery. Anesth Analg 98:578-584, 2004

54. Potpara TS, Polovina MM, Licina MM, Stojanovic RM, Prostran MS, Lip GY: Novel oral anticoagulants for stroke prevention in atrial fibrillation: focus on apixaban. Adv Ther 29:491-507, 2012

55. Rolfe S, Papadopoulos S, Cabral KP: Controversies of anticoagulation reversal in life-threatening bleeds. J Pharm Pract 23:217-225, 2010

56. Roquer J: Previous antiplatelet treatment and mortality in patients with intracerebral hemorrhage. Stroke 38:863-864, 2007 (Letter)

57. Roquer J, Rodríguez Campello A, Gomis M, Ois A, Puente V, Munteis E: Previous antiplatelet therapy is an independent predictor of 30-day mortality after spontaneous supratentorial intracerebral hemorrhage. J Neurol 252:412-416, 2005 


\section{Anticoagulant- and antiplatelet-related intracerebral hemorrhage}

58. Rossen JD, Chalouhi N, Wassef SN, Thomas J, Abel TJ, Jabbour PM, et al: Incidence of cerebral ischemic events after discontinuation of clopidogrel in patients with intracranial aneurysms treated with stent-assisted techniques. Clinical article. J Neurosurg 117:929-933, 2012

59. Saloheimo P, Ahonen M, Juvela S, Pyhtinen J, Savolainen ER, Hillbom M: Regular aspirin-use preceding the onset of primary intracerebral hemorrhage is an independent predictor for death. Stroke 37:129-133, 2006

60. Sansing LH, Messe SR, Cucchiara BL, Cohen SN, Lyden PD, Kasner SE: Prior antiplatelet use does not affect hemorrhage growth or outcome after ICH. Neurology 72:1397-1402, 2009

61. Schwammenthal Y, Tsabari R, Shenkman B, Schwartz R, Matetzky S, Lubetsky A, et al: Aspirin responsiveness in acute brain ischaemia: association with stroke severity and clinical outcome. Cerebrovasc Dis 25:355-361, 2008

62. Seidel H, Rahman MM, Scharf RE: Monitoring of antiplatelet therapy. Current limitations, challenges, and perspectives. Hamostaseologie 31:41-51, 2011

63. Sharma AK, Ajani AE, Hamwi SM, Maniar P, Lakhani SV, Waksman R, et al: Major noncardiac surgery following coronary stenting: when is it safe to operate? Catheter Cardiovasc Interv 63:141-145, 2004

64. Sibbing D, Schulz S, Braun S, Morath T, Stegherr J, Mehilli J, et al: Antiplatelet effects of clopidogrel and bleeding in patients undergoing coronary stent placement. J Thromb Haemost 8:250-256, 2010

65. Snoep JD, Hovens MM, Eikenboom JC, van der Bom JG, Huisman MV: Association of laboratory-defined aspirin resistance with a higher risk of recurrent cardiovascular events: a systematic review and meta-analysis. Arch Intern Med 167:1593-1599, 2007

66. Sorimachi T, Fujii Y, Morita K, Tanaka R: Predictors of hematoma enlargement in patients with intracerebral hemorrhage treated with rapid administration of antifibrinolytic agents and strict blood pressure control. J Neurosurg 106:250-254, 2007

67. Stetler WR, Chaudhary N, Thompson BG, Gemmete JJ, Maher CO, Pandey AS: Prasugrel is effective and safe for neurointerventional procedures. J Neurointerv Surg [epub ahead of print], 2012

68. Taberner DA, Thomson JM, Poller L: Comparison of prothrombin complex concentrate and vitamin K1 in oral anticoagulant reversal. BMJ 2:83-85, 1976

69. Thrift AG, McNeil JJ, Forbes A, Donnan GA: Risk of primary intracerebral haemorrhage associated with aspirin and nonsteroidal anti-inflammatory drugs: case-control study. BMJ 318:759-764, 1999

70. Toyoda K, Okada Y, Minematsu K, Kamouchi M, Fujimoto S, Ibayashi S, et al: Antiplatelet therapy contributes to acute de- terioration of intracerebral hemorrhage. Neurology 65:10001004, 2005

71. Tuhrim S: Aspirin-use before ICH: a potentially treatable iatrogenic coagulopathy? Stroke 37:4-5, 2006

72. van Aart L, Eijkhout HW, Kamphuis JS, Dam M, Schattenkerk ME, Schouten TJ, et al: Individualized dosing regimen for prothrombin complex concentrate more effective than standard treatment in the reversal of oral anticoagulant therapy: an open, prospective randomized controlled trial. Thromb Res 118:313-320, 2006

73. van Ryn J, Stangier J, Haertter S, Liesenfeld KH, Wienen W, Feuring M, et al: Dabigatran etexilate-a novel, reversible, oral direct thrombin inhibitor: interpretation of coagulation assays and reversal of anticoagulant activity. Thromb Haemost 103:1116-1127, 2010

74. Vilahur G, Choi BG, Zafar MU, Viles-Gonzalez JF, Vorchheimer DA, Fuster V, et al: Normalization of platelet reactivity in clopidogrel-treated subjects. J Thromb Haemost 5:82-90, 2007

75. Watanabe M, Siddiqui FM, Qureshi AI: Incidence and management of ischemic stroke and intracerebral hemorrhage in patients on dabigatran etexilate treatment. Neurocrit Care 16:203-209, 2012

76. Yasaka M, Oomura M, Ikeno K, Naritomi H, Minematsu K: Effect of prothrombin complex concentrate on INR and blood coagulation system in emergency patients treated with warfarin overdose. Ann Hematol 82:121-123, 2003

77. You JJ, Singer DE, Howard PA, Lane DA, Eckman MH, Fang $\mathrm{MC}$, et al: Antithrombotic therapy for atrial fibrillation: Antithrombotic Therapy and Prevention of Thrombosis, 9th ed: American College of Chest Physicians Evidence-Based Clinical Practice Guidelines. Chest 141 (2 Suppl):e531S-e575S, 2012

78. Yuan ZH, Jiang JK, Huang WD, Pan J, Zhu JY, Wang JZ: A meta-analysis of the efficacy and safety of recombinant activated factor VII for patients with acute intracerebral hemorrhage without hemophilia. J Clin Neurosci 17:685-693, 2010

79. Zhou W, Schwarting S, Illanes S, Liesz A, Middelhoff M, Zorn M, et al: Hemostatic therapy in experimental intracerebral hemorrhage associated with the direct thrombin inhibitor dabigatran. Stroke 42:3594-3599, 2011

Manuscript submitted January 15, 2013.

Accepted February 21, 2013.

Please include this information when citing this paper: DOI: 10.3171/2013.2.FOCUS1328.

Address correspondence to: Robert F. James, M.D., ECU Neurosurgical and Spine Center, 2325 Stantonsburg Road, Greenville, North Carolina 27834. email: jamesro@ecu.edu. 